Revista de Estudios Histórico-Jurídicos

[Sección historia del derecho chileno]

XLIII (Valparaíso, Chile, 2021)

[pp. 545-569]

\title{
LA GÉNESIS DEL ESTATUTO JURÍDICO PROCESAL SOBRE EL COBRO DE PENSIONES DE ALIMENTOS PARA MENORES EN CHILE: UNA INTERPRETACIÓN DESDE LA INFLUENCIA DE LOS PROCESOS SOCIALES (1912-1935)
}

[The genesis of the procedural legal statute on the payment of child support for minors in Chile: an interpretation from the influence of the social processes (1912-1935)]

\author{
Francesco Carretta MuÑoz* \\ Pontificia Universidad Católica de Valparaíso, Chile**
}

\section{RESUMEN}

En este estudio se intentará describir el origen de los institutos jurídicos vinculados al cobro de pensiones alimenticias en Chile que nacieron como una respuesta a las problemáticas sociales y jurídicas de principios del siglo XIX. Principalmente a partir de los conflictos económicos y culturales que afectaron a la infancia; el estatuto jurídico desigual que poseían los niños según si nacían o no bajo el matrimonio de sus padres y la insuficiencia del Código Civil para tutelar el derecho de alimentos que dio paso a las leyes especiales que surgieron entre los años 1912 y 1935.

Palabras clave

Procedimiento de familia - pensiones de alimentos - interés superior del niño cuestión social.
ABstract

This study will attempt to describe the origin of the legal institutes linked to the collection of alimony in Chile that were born as a response to the social and legal problems of the early nineteenth century related to this. Mainly from the economic and cultural conflicts that affected childhood; the unequal legal status that children had according to whether or not they were born under the marriage of their parents; and, the insufficiency of the Civil Code to protect the right to maintenance that gave way to the special laws that arose between the years 1912 and 1935.

\section{KEY WORDS}

Family procedure - child support best interest of the child - social question.

RECIBIDO el 9 de septiembre de 2020 y ACEPTADO el 29 de diciembre de 2020

* Académico de la Facultad de Derecho de la Pontificia Universidad Católica de Valparaíso. Correo electrónico: francesco.carretta@pucv.cl. ORCID 0000-0002-2552-8552. El autor agradece la colaboración de la abogada de la Corporación Administrativa del Poder Judicial Camila Letelier por la entrega de los valiosos datos empíricos que han servido para fundamentar este trabajo.

** Esta investigación fue hecha en el marco del proyecto Fondecyt regular $\mathrm{N}^{\circ} 1190329$ cuyo autor es el investigador responsable. 


\section{INTRODUCCIÓN}

Uno de los derechos especialmente sensibles para la protección de la infancia es el derecho de alimentos. Su importancia puede reflejarse en las palabras de Gabriela Mistral que, en su ponencia sobre los derechos del niño presentada en la Primera Convención Internacional de Maestros en Buenos Aires de 1928, señaló que en primer lugar los niños tienen: "Derecho a la salud plena, al vigor y a la alegría. Lo cual significa derecho a la casa, no solamente salubre, sino hermosa y completa; derecho al vestido y a la alimentación mejores. La infancia servida abundante y hasta excesivamente por el Estado, debería ser la única forma de lujo -vale decir, de derroche- que una colectividad honesta se diera, para su propia honra y su propio goce. La infancia se merece cualquier privilegio"1.

Esta importancia no solo es cualitativa según se desprende de las palabras de la poetisa; las causas judiciales donde incide este imperativo, según datos recientes, constituye el mayor volumen de casos que se tramitan en los juzgados de familia en Chile, cerca del 33\% de todos los ingresos anuales. Este caudal de expedientes se compone de aquellos que están en tramitación mediante un procedimiento ordinario, como también las que están en etapa de cumplimiento mediante el juicio ejecutivo sui generis que se genera a partir de ellas. Según datos concretos, estas ejecuciones alcanzan cerca del $27 \%$ del total de causas que se tramitan en esta materia ${ }^{2}$. Se trata de un gran porcentaje de incumplimientos que le deben hacer frente al problema de la falta de expedición de los métodos de apercibimiento y ejecución que establece la ley para conseguir el pago de este tipo de obligaciones.

A esto se suma el hecho de que para el cobro de las pensiones alimenticias la legislación chilena consagra un sistema de responsabilidad privada. Esto quiere decir que aquellos llamados a responder por el pago de la pensión de los niños, niñas y adolescentes (en adelante, NNA) son principalmente sus parientes, lo que en el fondo implica que el pago de la pensión no está garantizado. Esto significa que, si la pensión no se paga por aquellos miembros de su familia que según la ley están obligados a hacerlo, puede ocurrir que en última instancia los NNA no recibirán lo necesario para su subsistencia indefinidamente.

Es de presumir que todo lo dicho produce un alto grado de insatisfacción a los justiciables. Para cambiar este panorama, se han presentado en el último tiempo algunas mociones parlamentarias que buscan mejorar los mecanismos que establece la ley para perseguir el pago de este tipo de obligaciones. En los fundamentos que las motivan no se divisa antecedente histórico alguno que pudiera servir para un análisis más exhaustivo de las propuestas. Es más, una de

\footnotetext{
${ }^{1}$ Disponible en http://www.gabrielamistralfoundation.org. (Fecha de consulta: 8 de julio de 2020).

${ }^{2}$ Según datos extraídos desde el informe de análisis de las causas de alimentos ingresadas desde el año 2016 a junio de 2019 elaborado por el subdepartamento de modernización de la Corporación Administrativa del Poder Judicial (sin edición) y el reporte estadístico 2017 del Informe Anual de la Justicia del Instituto Nacional de Estadísticas, disponible en https://www. ine.cl/docs/default-source/justicia/publicaciones-y-anuarios/difusi $\% \mathrm{C} 3 \% \mathrm{~B} 3 \mathrm{n} /$ informe-anualde-justicia-2017.pdf?sfvrsn=2cc62c5b_2 [Fecha de consulta: 18 de junio de 2020].
} 
ellas pretende instaurar un mecanismo penal para sancionar el incumplimiento del deber alimenticio que ya existió en Chile desde el año 1935 hasta el año 1962, año en que fue derogada dada su ineficiencia. $\mathrm{Al}$ parecer, aunque parezca demasiado repetido, se les ha olvidado a los legisladores que quien no conoce la historia está condenado a repetir sus errores. Si bien estas mociones no son derecho vigente, por lo tanto, no están dentro del campo de observación de esta investigación, sirven para evidenciar el camino que puede tomar la voluntad de cambio que en esta materia la sociedad desea a través de sus legisladores.

De cualquier manera, éste se trata de un estudio historiográfico y, como tal, pretende exhibir los antecedentes que dieron pie a la normativa actual sobre el estatuto procesal para el cobro de pensiones alimenticias para NNA contenido en la actual ley $\mathrm{N}^{\circ} 14.908$ sobre abandono de familia y pago de pensiones alimenticias. Lo propositivo en ello, a parte de lo dicho líneas arriba, son las hipótesis que guían este trabajo. Estas son: i) es probable que las ideas con las que se elaboraron las normas reformadoras sobre el cobro de los alimentos para menores que nacieron a comienzos y durante la primera mitad del siglo XX surgieran a partir de la fisura que se abrió en la mirada patrimonialista que sobre estos asuntos poseían los juristas y legisladores de dicha época, a partir de las disputas que tuvieron lugar entre las facciones conservadora y de izquierda en el Congreso; ii) es factible que aquella grieta se haya abierto como una respuesta a las condiciones sociales y económicas del mencionado periodo que afectó notoriamente a la infancia, sobre todo bajo la influencia de la denominada c u e s t i ó n s o c i a l; y, iii) es posible que haya ciertas instituciones insertas en el régimen legal actual de cumplimiento de las pensiones de alimentos que hoy no se comprenden y que, sin embargo, pueden encontrar mayor claridad si se atiende a sus anales que se espera dar a conocer a través de esta obra.

Por último, lo adecuado hoy en día es hablar de niños, niñas y adolescentes. La intención del título es dejar constancia y reflejar el espíritu de una época donde aquel grupo etario se les denominaba m e n o res.

\section{Premisas}

1. Esta indagación se centra en el análisis de leyes procesales. Sin embargo, atendido el carácter accesorio del proceso, se subentiende que estas no pueden predicarse sin aludir al derecho de fondo al que sirven. De esta manera cabe recordar la dicotomía que existe entre el derecho adjetivo y sustantivo, y que todavía existen ciertas disquisiciones sobre los ámbitos que abarca una y otra disciplina ${ }^{3}$. Especialmente en el derecho de familia, donde es difícil divisar una frontera nítida entre ambas áreas. Con todo, es claro el hecho de que el proceso es un instrumento que sirve al derecho de fondo.

Hecha esta aclaración se previene que a lo largo de este trabajo en ocasiones se mencionarán aspectos sustantivos del derecho en examen; pero, con esta pre-

${ }^{3}$ Véase PÉrez Ragone, Álvaro, El impacto del diálogo entre derecho sustantivo y derecho procesal, en Revista Derecho del Estado. Universidad Externado de Colombia, 41 (2018), pp. 255-283. 
vención, también se quiere expresar que se hará sin la profundidad que pudiese esperar el lector. Por eso, se insiste en que no se pierda de vista que esta se trata de una pesquisa que busca desentrañar los aspectos procesales comprometidos en la cuestión que es donde se pondrá el acento necesario.

2. Acorde con la prevención mencionada en el párrafo anterior, debe explicarse que lo que se predica en este estudio no es preponderantemente sobre el derecho de alimentos en sí. A saber, la facultad amparada por el ordenamiento jurídico que un sujeto posee de exigirle a otro su manutención o como Vodanovic afirma: "el derecho que tiene determinadas personas en estado de necesidad de exigir alimentos a otras también determinadas, las cuales están obligadas a proporcionárselos por mandato de la ley o la voluntad de las partes o la unilateral de un tercero [...]"4. Este estudio se enfocará en la manera como el derecho de alimentos en abstracto se concreta en un crédito en favor de un niño y los mecanismos procesales para exigirlo. A esta forma de concreción la ley la denomina "alimentos devengados" que son la suma de dinero o especies que los progenitores deben pagar a sus hijos que se han determinado en cuanto a su monto y periodicidad en virtud de una sentencia o acuerdo por el que se han obligado ${ }^{5}$.

Desde ese punto de vista resulta ilustrativa la definición que Fueyo da sobre el particular: "se entiende por deuda alimenticia la prestación que pesa sobre determinadas personas, económicamente posibilitadas, para que alguno de sus parientes pobres, u otras personas que señale la ley, puedan subvenir a las necesidades de la existencia" ". Por cierto, esto no desconoce que este aspecto emana del derecho en abstracto que en palabras del mismo autor recién citado es una manifestación de derecho a la vida puesto que: "la función económica de este deber legal, se encuentra muy bien precisada: hacer posible la existencia de la persona"7. De ahí su vital importancia que hace que algunos autores lo categoricen como un derecho humano fundamental ${ }^{8}$.

3. La historia del tópico objeto de esta obra, dada la abundante información y extensión que hay sobre él es conveniente dividirla en tres periodos que, tal como una línea de tiempo, está marcada por tres hitos que reportan la necesaria problemática que motiva toda investigación histórica? ${ }^{9}$ El primer periodo, que será abordado en este trabajo, se identifica con los primeros intentos del Estado para regular los derechos de los niños, frente a las ingentes necesidades sociales que fueron pujando hacia la creación de estatutos jurídicos de protección más específicos que el contenido en el Código Civil. Esta etapa va desde principios del siglo pasado y corre hasta el año 1935 donde se dicta la ley $\mathrm{N}^{\circ} 5.750$ que cimenta

\footnotetext{
${ }^{4}$ Vodanovic Hakicka, Antonio, Derecho de alimentos ${ }^{4}$ (1987, Santiago, LexisNexis, 2004), p. 4.

${ }^{5}$ Caffarena de Jiles, Elena, De las pensiones alimenticias ${ }^{2}$ (1947, Santiago, Fallos del Mes, 1986), p. 34.

${ }^{6}$ Fueyo Laneri, Fernando, Derecho civil (Santiago, Imprenta y Litografía Universo, 1959), III, p. 554.

${ }^{7}$ Ibíd.

${ }^{8}$ Vodanovic Haklicka, Antonio, cit. (n. 4), pp. 3-4; Greeven Bobadilla, Nel, Derecho de alimentos como derecho bumano y apremios para obtener el cumplimiento (Santiago, Librotecnia, 2018), pp. 20-21.

${ }^{9}$ Febvre, Lucien, Los combates por la bistoria ${ }^{3}$ (1970, Barcelona, Ariel, 1982), p. 42.
} 
las bases de un estatuto específico para el cobro de las pensiones alimenticias que se sigue perfeccionando hasta el día de hoy.

El segundo periodo, al igual que el siguiente que esperan ser tratados en futuros manuscritos, comienza con la ley recién citada y sus posteriores reformas que finalizan con la sistematización y unión de varias leyes en una sola: la ley $\mathrm{N}^{\circ} 14.908$ del año 1962. Este lapso se caracteriza por el fracaso de la figura delictiva por el abandono de familia que contenía la ley del año 1935 y su abolición en el año 1949 que dio paso al sistema dual de cobro ejecutivo/compulsivo tal como se conoce hoy.

El tercer periodo se puede fijar entre el año 1962 y el año 2007 en que se verifican las últimas modificaciones importantes a la ley $\mathrm{N}^{\circ} 14.908$, a través de la ley $\mathrm{N}^{\circ}$ 20.152. Esta etapa está marcada notoriamente por la influencia de la Convención de Derechos del Niño en las sucesivas reformas que a partir de ella se introdujeron en el ordenamiento jurídico nacional. En especial con la promulgación de la ley $\mathrm{N}^{\circ} 19.985$ que establece la libertad de la investigación de la filiación y un nuevo estatuto filiativo a partir del cual se consagra la plena igualdad de los derechos de los NNA que desde ahí pasan a ser hijos sin denominación alguna que emane de su origen y que tuvo una influencia gravitante en la materia que es objeto de esta indagación.

\section{EstAdo DE LA CUESTIÓN A COMIENZOS DEL SIGLO XX}

La situación en Chile de finales del siglo XIX y a principios del siglo XX se enmarcó dentro de lo que algunos historiadores han llamado la c u e s t ín n s o c i al, que se extendió hasta aproximadamente el año $1920^{10}$. Aun cuando no es fácil de definir ${ }^{11}$, alude a las malas condiciones que reportó para la clase obrera el capitalismo, la industrialización y la urbanización descontrolada de esos tiempos que amenazó: "de ver despoblarse nuestro suelo por la doble acción de la mortalidad de los párvulos y la corriente de emigración que anualmente se apodera de millares de nuestros compatriotas" ${ }^{12}$. Este fenómeno dio paso a varios ensayos que daban cuenta de los problemas que afectaban a los sectores populares del país ${ }^{13}$. Como da cuenta la cita, los niños sufrieron de manera ingente los

${ }^{10}$ Valdivieso Fernández, Patricio, "Cuestión social” y Doctrina Social de la Iglesia en Chile (18801920): ensayo histórico sobre el estado de la investigación", en Revista Historia, 32 (1999), pp. 553-573; Grez Toso, Sergio, La "cuestión social" en Chile, ideas y debates precursores, 1804-1902 (Santiago, Dirección de Bibliotecas, Archivos y Museos, 1995); Milanich, Nara, Childhood, Class, and the State in Chile, 1850-1930 (Durham, Duke University Press), p. 20; Collier, Simon; SAter, William, A History of Chile, 1808-2002 (Cambridge University Press, 2004), p. 2808.

${ }^{11}$ Reyes Konings, Luis, La Cuestión Social en Chile: Concepto, problematización y explicación. Una propuesta de revisión historiográfica, en Estudios Históricos, 2 (2010), p. 5. Disponible en: http:/ / www.estudioshistoricos.org/edicion5/0502Cuestion_Social_en_Chile.pdf [Fecha de consulta: 6 de julio de 2020].

${ }^{12}$ Orrego Luco, Augusto, La cuestión social (Santiago, Editorial Barcelona, 1897), p. 2.

${ }^{13}$ Valdivieso Fernández, Patricio, Dignidad bumana y justicia: La historia de Chile, la politica social y el cristianismo 1880-1920 (Santiago, Editorial Pontificia Universidad Católica de Chile, 2006), p. 23; Urrutia, Cecilia, Niños de Chile (Santiago, Editorial Quimantú, 1972), pp. 1-92. 
embates de ese periodo que en último caso les significaba la muerte. La mitad de las defunciones en las ciudades correspondía a menores de edad ${ }^{14}$. Aunque estas penurias también drenaron en desnutrición, enfermedades infecciosas como el cólera y la viruela y el tifus producto del hacinamiento en los conventillos. A la par, cerca del $35 \%$ de los nacimientos correspondía a hijos ilegítimos ${ }^{15}$. De esta manera "la condición ilegítima de tantos niños chilenos fue hasta el año 1920 uno de los principales problemas sociales y morales en los que se centró la atención de los contemporáneos" 16 .

La ley civil contenía un esquema que diferenciaba entre hijos legítimos e ilegítimos y, respecto a estos últimos, los subclasificaba en naturales, de dañado ayuntamiento y simplemente ilegítimos. Esta fue una cuestión que venía corriendo desde las antiguas leyes coloniales españolas vigentes antes de la promulgación del Código Civil en el año 1855 que no se alteraron sustancialmente con la vigencia del Código de Bello ${ }^{17}$. Los hijos legítimos eran los que nacían al amparo del matrimonio de sus padres, mientras que los naturales eran los que, no siendo de dañado ayuntamiento, nacían fuera del matrimonio de sus progenitores, pero podían obtener el reconocimiento voluntario de su padre o madre por instrumento público o por testamento ${ }^{18}$. Los ilegítimos no eran reconocidos por sus padres y los de dañado ayuntamiento eran los que procedían de una relación sacrílega, incestuosa o adulterina. Estos últimos no podían reclamar ningún derecho en contra de sus progenitores ni tampoco podían ser voluntariamente reconocidos por estos, ni aun por matrimonio posterior ${ }^{19}$. La ley prohibía su reconocimiento por estimar aquellas relaciones como ilegales. Estos no podían intentar acciones destinadas a averiguar su progenie ni menos pedir alimentos ${ }^{20}$.

Para los hijos ilegítimos, no existía la posibilidad de investigar la filiación y solo se accedía a ella, como se mencionó en el párrafo anterior, por un acto intencionado de los progenitores que los transformaba en naturales. Estas limitantes eran recogidas por todos los códigos civiles latinoamericanos de la época, salvo en el argentino que permitía averiguar la filiación a través de cualquier medio de prueba ${ }^{21}$. Aspecto paradojal, si se considera la reforma que a este respecto se introdujo el 16 de noviembre de 1912 en el Código Civil francés del cual la

${ }^{14}$ Valdivieso Fernández, Patricio, Dignidad humana, cit. (n. 13), p. 69; Urrutia, Cecilia, cit. (n. 13), p. 29.

${ }^{15}$ Gazmuri Riveros, Cristián, Historia de Chile 1891-1994 (Santiago, Ril Editores, 2012), pp. 82-83.

${ }^{16}$ Valdivieso Fernández, Patricio, Dignidad bumana, cit. (n. 13), p. 74.

${ }^{17}$ Milanich, Nara, cit. (n. 10), pp. 41-43.

${ }^{18}$ Corte de Apelaciones de Santiago, sentencia de 29 de septiembre de 1922, en Revista de Derecho y Jurisprudencia, 23/1 (1926), pp. 36-39.

${ }^{19}$ Silva Bascuñán, Alejandro, Un siglo de evolución legislativa en lo familiar, en Revista de Derecho y Jurisprudencia, 49/9 (1952), p. 110.

${ }^{20}$ Claro Solar, Luis, Explicaciones de derecho civil chileno y comparado (Santiago, Editorial Jurídica de Chile, 1978), I, p. 277.

${ }^{21}$ Fernández Pradel, Arturo, Hijos naturales, ilegitimos o de dañado ayuntamiento, en Revista de Derecho y Jurisprudencia, 14/1 (1917), p. 147. 
mayoría de esos códigos son tributarios, que permitió la libre investigación de la paternidad ${ }^{22}$.

La diferenciación anterior incidía en el derecho en comento porque a partir de ella los hijos legítimos podían pedir alimentos congruos a sus padres cuales eran los que "babilitaban al alimentado para subsistir modestamente de un modo correspondiente a suposición social"23, mientras que los hijo naturales o simplemente ilegítimos, podían pedir alimentos necesarios que, en menor proporción, eran los que le "le dan lo que basta para sustentar la vida"24. La diferencia entre los dos últimos estaba en que los hijos naturales podían demandar alimentos habida consideración del vínculo familiar que los unía con sus padres a partir del reconocimiento voluntario de estos; en cambio, los simplemente ilegítimos como no poseían un vínculo filiativo con sus padres, solo se les otorgaba este precario derecho de alimentos que quedaba supeditado a una demanda cuyas posibilidades de éxito estaban sujetas a la confesión de la paternidad o maternidad que para este solo efecto se podía rendir en los tribunales. Era tan restrictiva esta norma que hubo jurisprudencia donde se discutió que, si para pedir los alimentos servía o no un hecho tan palmario como la confesión de paternidad hecha por el padre, aunque si bien no en sede judicial, sí en la partida de nacimiento del hijo ${ }^{25}$. Por cierto, a esta fecha aún no existían los Tribunales de Menores, por lo que esta acción se interponía para ante la justicia civil. Este cuadro que, desde una mirada actual resulta discriminador para los NNA, ya en 1916 levantaba las primeras quejas. Fernánez Pravel protesta en contra de esto y principalmente porque no le parecía que a los hijos ilegítimos se les vedara el derecho de averiguar su ascendencia puesto que a su juicio era "injusto y absurdo castigar en los hijos la falta de sus padres"26.

Hasta esa fecha y un buen tiempo después el Código de Bello, sin perjuicio del esquema filiativo visto recién, no daba una respuesta adecuada al panorama de menoscabo de la niñez en general. En efecto, poseía un estatuto que primordialmente favoreció la seguridad del patrimonio de los niños por sobre sus intereses personales y que regulaba más los derechos de los padres sobre sus hijos que el derecho de estos mirados de manera autónoma ${ }^{27}$. Así, la fuerza de las circunstancias hizo necesaria la creación el año 1912 de un cuerpo legal específico de protección de sus derechos. Esta fue la ley $N^{\circ} 2.675$ sobre Protección a la Infancia Desvalida. Un breve estatuto que contiene 12 normas que intentaron remediar la situación de muchos niños que por aquella época se encontraban en una situación desventajosa al interior de sus familias. Es así como esta ley afectó las amplias atribuciones que sobre ellos poseían sus padres, las que ceden en favor del Estado,

${ }^{22}$ Delzons, Luis, La investigación de la paternidad, en Revista de Derecho y Jurisprudencia, 10/1 (1913), pp. 217-229.

${ }^{23}$ Artículo 323 del Código Civil de 1855.

${ }^{24}$ Ibíd.

${ }^{25}$ Corte de Apelaciones de Santiago, sentencia de 24 de diciembre de 1919, en Revista de Derecho y Jurisprudencia, 19/7 (1921), pp. 309-311.

${ }^{26}$ Fernández Pradel, Arturo, cit. (n. 21), p. 148.

${ }^{27}$ Incluso para algunos el Código Civil fue considerado como "el enemigo contra el cual ha debido luchar el nuevo derecho de Menores”. Gajardo Contreras, Samuel, Protección de menores (Santiago, Editorial Jurídica de Chile, 1955), p. 67. 
pero solo en aquellos casos donde se podía presumir abandono y desprotección. Por ejemplo, se presumían de derecho estas circunstancias: " $1 .{ }^{\circ}$ Cuando elpadre no velare por la crianza, cuidado personal $i$ educación del hijo, al extremo de que éste se encuentre sin hogar ni medios de subsistencia; $2{ }^{\circ}$ Cuando el padre consintiere en que el bijo se entregue, en lugares públicos, a la vagancia o a la mendicidad, sea en forma franca, sea bajo el pretexto de una profesión u oficio; $3{ }^{\circ}$ Cuando el menor se entregare habitualmente a la prostitución o a la embriaguez; $4 .{ }^{\circ}$ Cuando el impúber fuere encontrado al servicio de acróbatas, titiriteros, saltimbanquis, domadores de fieras, casas de prostitución, de juegos u otras semejantes" 28 .

Estas causales, como las otras que aparecen en la ley, no abarcaban otro tipo de maltratos que no constituyeren situaciones graves. Ello, porque en esos años al interior del grupo familiar no era raro el castigo físico que encontraba un cierto aval en la norma civil que contemplaba la facultad de castigar y corregir moderadamente a los hijos ${ }^{29}$. Incluso, cuando esto no era suficiente podían los padres ordenar la detención de sus hijos en una institución correccional ${ }^{30}$. Aunque hoy parece desproporcionado y difícil pensar que aquel mecanismo se haya utilizado en forma efectiva, una jurisprudencia de 1913 da cuenta que la norma no era letra muerta. En ella se expresa que se impuso a r r e s to c or re c c i o n a l en contra de una niña de 19 años, a solicitud de su padre, porque de acuerdo con la regla en comento, el tribunal encontró mérito suficiente para decretarlo. Esto a su vez provocó que la niña fuera enviada a la casa del Buen Pastor que era un establecimiento de detención para mujeres ${ }^{31}$.

A pesar de las limitaciones dadas por el restringido ámbito de aplicación de esta ley, sí es interesante destacar que significó un aporte en la tutela adjetiva de los alimentos para los niños en aquella disposición que aprobaba dictar una medida cautelar, cuando estos eran confiados provisionalmente al cuidado de un establecimiento de reforma o beneficencia. En esos casos la norma permitía fijar los alimentos que debían pagar los padres al orfanato una vez que la medida se adoptaba ${ }^{32}$.

Es de suponer que todo el escenario mundial de vulneración de los derechos de la infancia que fue el fundamento de la Declaración de Ginebra de 1912, suscrita por la Sociedad de Las Naciones en 1924 y el Decálogo de los Derechos del Niño de Montevideo, ambos firmados por Chile, se pusieron sobre la mesa de la Conferencia Panamericana del Niño realizada en Santiago el año 1924 y pujaron para que se crearan leyes más eficientes. En esta reunión internacional se intentaron idear vías concretas de solución que se centraron en necesidades urgentes como la alimentación y el vestuario ${ }^{33}$. Esto, a su vez, presumiblemente

\footnotetext{
${ }^{28}$ Artículo 1 de la ley $\mathrm{N}^{\mathrm{o}} 2675$.

${ }^{29}$ Rojas Flores, Jorge, Historia de la infancia en el Chile repúblicano, 1810-2010 (Santiago, Junji, 2010), p. 141.

${ }^{30}$ Artículo 233 del Código Civil de 1855.

${ }^{31}$ Corte de Apelaciones de Santiago, 24 de julio de 1913, en Gaceta de los Tribunales, (1913), pp. 3076-3077.

${ }^{32}$ Artículo 4 de ley $\mathrm{N}^{\circ} 2.675$ de 4 de septiembre de 2012.

${ }^{33}$ Rojas Flores, Jorge, Juegos y alegrias infantiles, en SAgredo BAEZA Rafael; GAZMURi RiveRos, Cristián (eds.), Historia de la vida privada en Chile, el Chile moderno. De 1840 a 1925 (Santiago, Taurus, 2011), II, pp. 350-351.
} 
impregnó el ambiente jurídico de la época que junto a otros factores llevó a la dictación de la ley $\mathrm{N}^{\circ} 4.447$ de 1928 que significó el primer paso desde la caridad privada a la pública mediante la creación de la Dirección General de Menores ${ }^{34}$.

\section{LA Ley de Menores Nº 4.447. El PRimer APORTE Específico para LA} TUTELA EFECTIVA DEL DERECHO DE ALIMENTOS

1. Hacia el año 1928 la situación social y económica en Chile que afectaba directamente a la infancia no había cambiado mutatis mutandi la necesidad de mejorar la tutela judicial de los niños tampoco. En este orden de ideas el motivo principal que se aprecia en la discusión parlamentaria que originó esta ley está impregnado por aquel contexto social que convergía durante esos años en que las tasas de natalidad en Chile eran altas, a la vez que las de mortalidad infantil aumentaban considerablemente ${ }^{35}$. Aparte de lo dicho, llama la atención que otra de las causas que motivó la ley, es lo que los parlamentarios llamaron el rela jo moral del progenitor, que vieron como una fuente fecunda de la infancia desvalida $^{36}$, entendido aquel defecto como la falta de compromiso o, derechamente, abandono del padre hacia su familia que según varios observan iba en aumento por aquella época ${ }^{37}$. En mérito de ambos factores nace la Ley de Menores $\mathrm{N}^{\circ}$ 4.447 que es publicada el 23 de octubre de 1928. Destaca el hecho de que esta ley elevó de 10 a 16 años la ausencia de responsabilidad delictual. Gajardo señala que a partir de esta ley se abandona la idea de expiación y castigo con que era tratado el niño por el Código Penal y se abre paso al entendimiento de que un NNA no es un ser humano en miniatura, sino que un sujeto con características autónomas e independientes a la de los adultos ${ }^{38}$.

Esta ley es citada por Turner como aquella que instaura la doctrina de los niños en situación irregular cuyos destinatarios son aquellos NNA que se encuentran en una situación de precariedad física o moral ${ }^{39}$. Desde una perspectiva actual, se ha dicho que esta doctrina no marcó un buen periodo para la protección de los derechos de la infancia, pues se acostumbraba a ver al niño como un problema que había que solucionar, más que como un sujeto de

\footnotetext{
${ }^{34}$ Mann, Wilhelm, Luchando por nuevas formas de vida (Santiago, Biblioteca Fundamentos de la Construcción de Chile, 2011), I, p. 140; Ossa Reygadas, Marta, Tribunales de Familia, en Revista de Derecho y Jurisprudencia, 66/2 (1969), p. 43.

${ }^{35}$ Schonhaut Berman, Luisa, Profilaxia del Abandono: Cien Años de Protección de la Infancia en Chile, en Revista Chilena de Pediatría 81/4 (2010), pp. 304-312; Rojas Flores, Jorge, Historia de la infancia, cit. (n. 29), pp. 424-425; Milanich, Nara, cit. (n. 10), p. 19.

${ }^{36}$ Actas de discusión legislativa del proyecto de ley sobre responsabilidad paterna y pago de pensiones alimenticias, sesiones 1933-1955 (Santiago, Biblioteca del Congreso Nacional, 1933), p. 2282.

${ }^{37}$ Ibíd., passim.

${ }^{38}$ Gajardo Contreras, Samuel, Los derechos de los niños y la tiranía del ambiente (Santiago, Editorial Nascimiento, 1929), p. 51; Carretta Navea, Darío, La policía de menores. Estudio sobre la delincuencia de menores y un método directo de prevención (Concepción, Universidad de Concepción, 1970), p. 53.

${ }^{39}$ Turner Saelzer, Susan, Los tribunales de familia, en Revista Ius et Praxis, 2/8 (2002), pp. 413-443.
} 
protección ${ }^{40}$. Además, está dirigida esencialmente a los niños que se encuentran en situación de vagancia o mendicidad, lo que no cambiaba radicalmente y en el fondo el esquema que ya había establecido la ley de $1912^{41}$.

Sin embargo, puede que no se haya advertido que esta normativa jugó un rol fundamental en la tutela judicial de los NNA ya que constituyó el primer hito en este aspecto. A partir de ella se creó el primer tribunal especializado de menores en Chile ${ }^{42}$. Aunque estos tribunales no pasaron a formar parte del Poder Judicial en ese momento, la presencia de magistrados exclusivamente dedicados a la resolución de las materias atingentes a la infancia amainaba el reproche de la falta de especialización que los jueces ordinarios podrían manifestar en estas materias ${ }^{43}$. En opinión del juez Gajardo, quien fue el primero que desempeñó dicha función en el primer Tribunal de Menores de Santiago, "los jueces del derecho común resultan incompetentes por cuanto su hábito profesional les orienta a soluciones jurídicas y abstractas de los códigos ordinarios y ellos no satisfacen al espíritu moderno de la protección infantil"'44.

La principal y novedosa característica de los juicios que se tramitaba ante ellos era que se desarrollaban mediante un procedimiento verbal y sin forma de juicio, lo que naturalmente se avenía con la expedición que se requería para atender este tipo de asuntos ${ }^{45}$. No obstante, la jurisprudencia al poco tiempo se encargaría de aclarar que el hecho de que se tramitara sin formas preestablecidas no significaba la ausencia de emplazamiento al demandado ${ }^{46}$. Incluso algunos autores estimaban que debía tramitarse conforme a las reglas del procedimiento sumario $^{47}$. Su competencia abarcaba todas las materias que pudieran afectar a los NNA, especialmente las referidas a la inhabilidad física o moral de sus padres para detentar su cuidado, problemas relacionados con la patria potestad o al maltrato

\footnotetext{
${ }^{40}$ BeLoff, Mary, Modelo de la protección integral de los derechos del niño y de la situación irregular. Un modelo para armary otro para desarmar, en Justicia y derechos del niño (Santiago, UNICEF, 1999), pp. 9-21

${ }^{41}$ Esta tesis con el tiempo se va atenuando progresivamente en favor de abarcar no solo a los niños que se encontrasen en una situación irregular, sino que se va expandiendo a todos los niños independiente de su condición a los que se les concede una mayor autonomía frente a los derechos y deberes que sus padres tienen sobre ellos. Esto va de la mano de la influencia de las declaraciones de los derechos del niño que antecedieron a la Convención cuyos principios se fueron plasmando en las sucesivas reformas a esta ley, hasta llegar el año 1967 con la dictación de la Ley $\mathrm{N}^{\mathrm{0}}$ 16.618. A su turno, esta se ha ido reformando hasta el día de hoy con la influencia de los principios inspiradores que establece la Convención de los Derecho del Niño de 1990. Este tratado internacional sobre derechos humanos inaugura una nueva fase en los derechos de la infancia denominada de la p r o te c c ión in tegral de los derechos del $\mathrm{n}$ i ñ o que cambia la perspectiva hacia una óptica que regula los derechos de los niños con mayor independencia de los deberes y derechos que sus padres tiene sobre ellos.

${ }^{42}$ Véase artículos 13, 14, 15 y 16 de la ley No 4.447 de 23 de octubre de 1928.

${ }^{43}$ Gajardo Contreras, Samuel, Memorias de un juez (Santiago, Editorial Divulgación, 1957), pp. $9-10$.

${ }^{44}$ Gajardo Contreras, Samuel, Protección de menores, cit. (n. 27), p. 57.

${ }^{45}$ Artículo 26 de la ley $\mathrm{N}^{\circ} 4.447$ de 23 de octubre de 1928.

${ }^{46}$ Aguayo Lira, Julio, La ley 5750 sobre abandono de familia y pago de pensiones alimenticias. Análisis y crítica (Santiago, Universidad de Chile, 1944), pp. 21-23.

${ }^{47}$ Ibíd., p. 21.
} 
que estos pudiesen sufrir por parte de terceras personas. Además, se aplicaba a los menores de 20 años según disponía un artículo que resultaba bastante ambiguo pues parecía chocar con el rango etario que para los menores establecía el derecho común en ese entonces, es decir, 25 años. Señalaba: "para efectos de la aplicación de esta ley se considerados menores todos los seres humanos que no habian cumplido 20 años'48. Esto produjo algunas dudas interpretativas en su aplicación que serán vistas más adelante. Lo que no quedaba claro era la competencia territorial de los tribunales para conocer de estos asuntos ya que no había norma que la determinara por lo que se pensaba que tanto el juez del domicilio del menor, como del padre o madre podían ser competentes, incluso todos ellos al unísono si los padres estaban separados en cuyo caso primaba la regla por la cual el juez que haya prevenido en el conocimiento del asunto excluía a los demás ${ }^{49}$.

Este tipo de procedimiento también resultó aplicable a la solicitud de alimentos con la ventaja de su rapidez, puesto que, luego de notificado el progenitor, si éste concurría al comparendo que era citado, se podía promover un acuerdo con los demandantes, o se dictaba a viva voz la sentencia que determinaba la pensión ${ }^{50}$. La deficiencia podía venir después si el alimentante no pagaba, puesto que, para el cobro, se debía recurrir a los tribunales ordinarios para el embargo y remate de sus bienes, con la consiguiente demora y posibilidad que el alimentante usara maniobras abusivas para dilatar el proceso en su favor. Además, en consonancia con los motivos vistos en la discusión parlamentaria señalada líneas arriba, resultaba inoficioso perseguir a aquellos padres que ocultaban su patrimonio. El tribunal quedaba inerme ante "estos padres indolentes. En el juzgado aseguran carecer en absoluto de recursos, pero visten bien, se divierten y viven amancebados" ${ }^{\prime 2}$. De cualquier manera, esta ley causó un notorio impacto social que vino a solucionar lo que a esa fecha era un problema ingente de abandono de niños por parte de sus progenitores, según cuenta el juez Gajardo. Efectivamente, una vez que se enteraron de su vigencia, un gran número de madres abandonadas acudían a tribunales solicitando alimentos para sus hijos ${ }^{52}$.

Desde un punto de vista orgánico la promulgación de esta normativa produjo la existencia de tres tribunales que podían converger en el conocimiento y ejecución de las pensiones. Cuestión que es importante destacar para el subsiguiente análisis. Para la determinación del derecho y el monto de los alimentos, tratándose de menores de 20 años, el tribunal de menores que debía tramitar los pleitos conforme a las normas del nuevo procedimiento. Para el mismo asunto, tratándose de mayores a esa edad (que a esa fecha seguían siendo menores) o si se trataba de alimentos solicitados por menores y mayores conjuntamente, los tribunales ordinarios de justicia a través del procedimiento ordinario de cognición. Para el cobro de las pensiones alimenticias impagas en todos los casos se aplicaba el procedimiento ejecutivo que se gestionaba de acuerdo con las reglas generales

\footnotetext{
${ }^{48}$ Artículo 3 de la ley $\mathrm{N}^{\circ} 4.447$.

${ }^{49}$ Gajardo Contreras, Samuel, Los derechos de los niños, cit. (n. 38), p. 115.

${ }^{50}$ Ibíd., p. 96.

${ }^{51}$ Ibíd., p. 97.

${ }^{52}$ Ibíd., p. 96.
} 
del procedimiento ordinario establecido para las materias patrimoniales. Esta última alternativa provocaba un doble inconveniente tratándose de las pensiones reclamadas exclusivamente para niños. Por una parte, producía una dualidad de tribunales, el de menores para la determinación del derecho y uno civil ordinario para la ejecución. Por la otra, una dualidad contradictoria de procedimientos, uno expedito para la fijación del derecho y uno engorroso para la ejecución. Respecto a este último se temía que, aparte de la posibilidad de que el deudor ocultara bienes, como fue señalado en el párrafo anterior, "ejercitará toda clase de recursos dilatorios como táctica judicial" ${ }^{3}$, cuestión que no tardó en ser recogida en las modificaciones que luego acontecerían como se verá más adelante. Por último, tratándose de menores de edad entre 20 y 25 años, como no había un procedimiento especial establecido para ese rango etario, tanto el procedimiento para determinar el monto de la pensión como la ejecución quedaban sujetos a la regla general: en ambos casos debía acudirse a un procedimiento ordinario de cognición y ejecución.

2. Paradojalmente, a esa fecha muchas normas procesales específicas para la tramitación de un juicio sobre alimentos se encontraban en el Código Civil desde sus inicios, sin que ello quite el hecho de que en la mayoría de las materias de fondo y forma el Código de Bello era insuficiente en asuntos relacionados con la protección de la infancia, como se ha dicho antes. Algunas de estas normas se mantienen casi sin modificaciones hasta estos días. Estas son las relativas a la legitimación subsidiaria de los abuelos para el pago de los alimentos, la concerniente a la obligación de prestar alimentos mientras se ventila el juicio que los determina; las normas referidas a la legitimación activa y pasiva que, en términos simples, significan la forma como la ley contesta específicamente a las interrogantes: ¿quién puede demandar judicialmente el pago de una pensión? y ¿contra quién se puede dirigir la demanda ${ }^{54}$

La disposición más controversial era aquella que disponía que las pensiones se deben "desde la primera demanda i se pagarán por mesadas anticipadas", cuya oscuridad se sembró en la jurisprudencia dispar que se dictó en base a ella ${ }^{56}$. Algunos fallos consideraban que la norma se utilizaba para suplir el silencio de la sentencia en el caso que en ella no se especificara la fecha a partir de la cual se pagarían los alimentos; otros, suponían que la norma se refería al hecho de que el estado de necesidad del alimentario debía entenderse desde el momento en que presentaba la demanda, por eso era justo que se le comenzara a pagar desde ahi ${ }^{57}$. En todo caso, como la norma se ubicaba en el estatuto que correspondía a la descendencia

\footnotetext{
${ }^{53}$ Ibíd., p. 150.
}

${ }^{54}$ Romero Seguel, Alejandro, Curso de derecho procesal civil (Santiago, Editorial Jurídica de Chile, 2006), I, pp. 23-24; Consolo, Claudio, Spiegazioni di diritto processuale civile (Torino, Giappichelli Editore, 2014), I, p. 529.

${ }^{55}$ Artículo 331 del Código Civil de 1855.

${ }^{56}$ Corte de Apelaciones de Santiago, sentencia de 23 de junio de 1921, en Revista de Derecho y Jurisprudencia, 20/1 (1921), pp. 461-465; Corte de Apelaciones de Santiago, sentencia de 11 de enero de 1929, en Revista de Derecho y Jurisprudencia, $27 / 1$ (1930), pp. 139-142.

${ }^{57}$ Véase Repertorio de legislación y jurisprudencia chilena: Código Civily leyes complementarias (Santiago, Editorial Jurídica de Chile, 1996), II, p. 171. 
legítima, se entendió que para esta clase de hijos el derecho se originaba desde su nacimiento, y su cobro, en virtud del tenor de la norma, se podía producir después.

Expresión similar se encontraba en las reglas aplicables para los hijos simplemente ilegítimos: "los alimentos suministrados por el padre o la madre correrán desde la primera demanda" ". En este caso la "primera demanda" expresaba que tanto el derecho como el cobro tenían su génesis en el juicio, no el origen de la existencia-nacimiento- legal de la persona. Ha de recordarse que estos hijos no eran reconocidos por sus padres y solo tenían este limitado derecho a demandarlos por alimentos. Aunque en este caso con una peculiar excepción, según se consignaba en la segunda parte de la misma norma. En efecto, si los alimentos se pedían por esta clase de hijos dentro del año contado desde su nacimiento, su representante tenía el derecho a cobrar ese año y los gastos que hubiese irrogado el embarazo y el parto. Como se aprecia, estos son hechos anteriores a la interposición de la demanda. Los alimentos tenían en este caso, por así decirlo, un efecto retroactivo.

Como quiera que sea, dicha frase era un elemento delimitador del cobro de los alimentos porque de acuerdo con ella el legislador pretendía dejar en claro desde cuando el derecho se podía convertir en una deuda liquidable exigible por el alimentario. En otras palabras, con esto quedaba claro que los alimentos se pagarían solo desde que se reclamaban judicialmente a través de un juicio. Con esto se evita el contrafuerte que se puede producir en esta materia en el pensar que las pensiones alimenticias podrían exigirse desde el nacimiento. En ese caso como una suerte de indemnización de perjuicios por el tiempo intermedio entre dicho evento y el momento de la interposición de la acción que, dicho sea de paso, podría ser un trecho bastante largo, si se tiene en cuenta que el derecho de alimentos es imprescriptible ${ }^{59}$.

${ }^{58}$ Artículo 290 del Código Civil de 1855.

${ }^{59}$ Esta norma vigente actualmente en el artículo 331 del Código Civil sigue causando algunas dudas interpretativas en la jurisprudencia. Porque, si se considera que un juicio es una sucesión de varios actos procesales que corren desde la demanda y así sucesivamente hasta que se dicta la sentencia, da a entender que los alimentos se deben desde el primer acto procesal y con su sola presentación. En ese sentido: "lo anterior importa una excepción a la norma general según la cual las resoluciones judiciales sólo se cumplen desde que quedan ejecutoriadas o desde que causan ejecutoria en conformidad a la ley". Corte Suprema, sentencia de 19 de enero de 2009, disponible en: https://app.vlex.com/\#search/content_type:2/\%22primera+demanda $\% 22$ / WW/vid/55557068 [Fecha de consulta: 23-06-2020] Esto conlleva entender que, frente a una eventual controversia sobre el monto de pensiones adeudadas, estas serán cobradas con anterioridad a la dictación de la sentencia que las determina e incluso antes que la demanda sea notificada. Pero esto no es así, porque como se intentó reflejar de los anales de la norma se desprende que lo único que quiere decir con aquella alocución es que los alimentos se deben desde el juicio en que se piden, no desde que el hecho que los origina cual es la existencia legal de toda persona que principia al nacer. En otras palabras "primera demanda" debe entenderse como sinónimo de juicio. En todo caso, esto generaba mayores dudas antes de la modificación que introdujo la ley $\mathrm{N}^{\circ} 20.15$ del año 2007 a la ley $\mathrm{N}^{\circ} 14.908$ que obligó al juez a pronunciarse sobre los alimentos provisorios en la resolución que admite a tramitación la acción alimenticia. 
IV. LA LEY N ${ }^{\circ} 5.750$ SOBRE ABANDONO DE FAMILIA Y PAGO DE PENSIONES ALiMENTICIAS DE 1935. El INICIO DE UN ESTATUTO ESPECífiCO Y SISTEMÁTICO PARA PERSEGUIR EL PAGO DE LOS ALIMENTOS

1. Los problemas económicos y sociales en Chile a la época de discusión de la ley que abre paso a este acápite no habían cesado. Aún surgían conflictos en los hogares chilenos producto de la industrialización que seguía conminando a muchas familias al traslado desde el campo a la ciudad y al hacinamiento en conventillos. Chile viene saliendo de la denominada cuestión social, pero se encuentra de frente con la crisis económica más grande que ha visto la humanidad ${ }^{60}$. Son tiempos coetáneos a la gran depresión económica de los Estado Unidos de Norteamérica que se prolongó durante toda la década de 1930. Este fenómeno produjo una disminución abrupta de las exportaciones de cobre y salitre, lo que produjo en el país un problema económico, político y social de proporciones ${ }^{61}$. Esto no fue ignorado en la exposición de motivos de la ley cuyo corolario encuentra cabida en las palabras del diputado Pérez "El señor Presidente y la Honorable Cámara se han dado cuenta, de cómo la opinión pública ha recibido con entusiasmo este proyecto que vendrá a resolver un grave problema social"'62. Esto a su vez repercutió en los NNA en la medida que la precariedad económica no solo los afectaba a ellos, sino que a sus progenitores quienes veían mermadas sus posibilidades de sustento familiar. Para colmo, el otro de los males que afectaba a la niñez de ese entonces que era la ilegitimidad de los hijos que venía corriendo desde principios de siglo, a partir de la cual se veían impedidos de reclamar plenamente la manutención de sus padres ${ }^{63}$.

Es por ello por lo que la ley 5.750 de 1935 intentó responder en alguna medida a las necesidades antes dichas. A partir de su promulgación se abre el camino al derecho a la igualdad y no discriminación de los NNA y fue el punto de partida para sucesivas reformas que culminan en las postrimerías del siglo XX cuando se deroga por completo la que a esas alturas se consideraba una de las "situaciones de discriminación más odiosas de nuestra legislación" ${ }^{64}$, que implicaba la diferenciación de la prole como ya se ha hablado en este estudio. Los motivos de esta ley obedecieron al hecho de que los niños nacidos fuera del matrimonio de sus padres iban en un severo aumento. Se contabiliza que entre 1898 y 1920 entre el 32 al $38 \%$ de los nacimientos correspondían a hijos ilegítimos ${ }^{65}$. Así, esta ley incorporó modificaciones al Código Civil de suma importancia y abrió un cauce que se fue expandiendo progresivamente a través de los años hacia

\footnotetext{
${ }^{60}$ Collier, Simon; SATer, William, cit. (n. 10), p. 2808.

${ }^{61}$ Ibíd., p. 3206.

${ }^{62}$ Actas de discusión legislativa, cit. (n. 36), p. 2289.

${ }^{63}$ Santelices, María, El servicio social frente al problema de la madre soltera y su bijo, en Revista Servicio Social, 12/4 (1938), pp. 151-197.

${ }^{64}$ Etcheberry Court Leonor; Veloso Valenzuela, Paulina; Muñoz Sánchez, Andrea, El nuevo estatuto filiativo y las modificaciones al derecho sucesorio, a la luz de las normas y principios de la ley $N^{\circ} 19.585$ (Santiago, Sernam, 1999), p. 7.

${ }^{65}$ Valdivieso Fernández, Patricio, Dignidad humana, cit. (n. 13), p. 68; SAntelices, María, cit. (n. 63), p. 151.
} 
la plena igualdad del derecho de alimentos de los hijos, tanto en su titularidad, como en cuanto a su monto. El punto de inicio fue la completa supresión de la clasificación de los hijos de dañado ayuntamiento, quienes pueden ser reconocidos como naturales a la par que este tipo de hijos ahora podía ser legitimado por el matrimonio de sus padres. También, se inaugura una exigua posibilidad de seguir la pista de la paternidad ilegítima en forma restringida y estática ${ }^{66}$, para no decir engorrosa, con un limitado efecto que era únicamente reclamar los alimentos ${ }^{67}$.

Como es consustancial a reformas legislativas de envergadura como ésta, esta modificación no estuvo exenta de polémica entre el ala conservadora y liberal del Congreso, puesto que para los primeros con ella "lo único que se persigue es dar patente a los hombres casados para que puedan procrear hijos fuera del matrimonio" 68 para los segundos, en cambio: "Está bien que para 80 o 100 años atrás tuviéramos esta división, que se mirara a estos hijos como hijos de nadie y se les dejara completamente abandonados por la sociedad; pero hoy, frente al progreso ideológico y el ambiente social existente, tan distinto al de aquella época cerrada, no tenemos para qué mantener esta categoría de parias en nuestra sociedad" ${ }^{69}$. De cualquier manera, en las actas de conformación de la ley se puede ver el fundamento primigenio en la pretendida igualdad: la justicia debe conceder derechos a personas que no tienen culpa alguna en los actos o delitos de sus padres de tal manera de remediar "profundas injusticias sociales" 70 .

2. Esta normativa vino a llenar los vacíos reseñados en el párrafo anterior sobre la forma y el procedimiento de reclamar judicialmente las pensiones alimenticias por los NNA mediante la instauración de un procedimiento que permitió que la acción de alimentos sea tramitada en forma sencilla, rápida y eficaz ${ }^{71}$. De tal manera, esta ley se puede considerar como el inicio del estatuto procesal sobre la determinación y ejecución de derecho de alimentos y la base del procedimiento por el incumplimiento del deber de alimentos que los padres tienen para con sus hijos que en lo sustancial ha conservado su estructura basal por más de 80 años. Antes de ella, según se exploró en los capítulos anteriores, las leyes especiales y civiles solucionaban algunas cuestiones relacionadas al cobro, pero no existía el diseño de un procedimiento específico para la tramitación de estos asuntos. Todos los mecanismos eran dispersos e insuficientes y no aseguraban la expedición que requería la ejecución de las pensiones alimenticias ${ }^{72}$.

De esta manera, vino a cohesionar en un solo cuerpo legal las formas proce-

${ }^{66}$ Abeliuk Djimino, Joyce; Cerri López, Ximena, Investigación de la paternidad ilegítima y reconocimiento forzado de la paternidad, en Revista de Derecho y Jurisprudencia, 75/1 (1978), pp. 40-43.

${ }^{67}$ Reforma que no estuvo exenta de disputa por la más autorizada doctrina de le época. Véase Silva Bascuñán, Alejandro, cit. (n. 19), p. 111.

${ }^{68}$ Actas de discusión legislativa, cit. (n. 36), p. 132.

${ }^{69}$ Ibíd., p. 152.

${ }^{70}$ Ibíd., pp. $739-740$.

${ }^{71}$ Somarriva Undurraga, Manuel, Derecho de familia (Santiago, Editorial Nascimento, 1946), p. 521; Fueyo Laneri, Fernando, cit. (n. 6), p. 592.

${ }^{72}$ Actas de discusión legislativa, cit. (n. 36), p. 138. Por ejemplo, antes debía iniciarse un juicio ejecutivo por cada pensión impaga. Es decir, un juicio cada mes, lo que evidentemente disuadía la posibilidad de iniciarlos. 
sales aplicables que, impregnadas por el sensible derecho de fondo al que sirven, se vierten en un procedimiento expedito para paliar las necesidades alimenticias que afectaban a los niños, no cubierta a esa fecha" ${ }^{73}$. De tal forma "La finalidad de este proyecto tiende a modificar disposiciones del Código Civil que, aunque inspiradas en el mismo espíritu humanitario que lo informa, han demostrado en la práctica su ineficiencia, tanto por deficiencias del procedimiento establecidos para su aplicación" ${ }^{\prime 74}$. En este orden de ideas, los lineamientos fundamentales del proyecto de ley fueron: "aplicar sanciones penales para el delito de abandono de familia y para los que burlen el pago de pensiones alimenticias; amplía el derecho de los hijos ilegítimos para pedir alimentos; y establece procedimientos rápidos para ejercitar las acciones civiles y criminales en esta materia" 75 .

El tercer objetivo reseñado en la moción transcrita recién se asienta en dos ideas matrices: simplificar el juicio de alimentos y adecuar el procedimiento de apremio a fin de darle una mayor expedición. Con ese fin, se modifica la regla de competencia que existía hasta entonces por una que le hace más fácil las cosas al alimentario que debe considerarse como la parte débil de este tipo de relación procesal. Así, se determinó que el tribunal llamado a conocer es el del domicilio del demandante. En buenas cuentas el domicilio del menor. Además, se estableció que el procedimiento para el conocimiento de estas materias sería las propias del juicio ordinario, sin los trámites de réplica y dúplica y los alegatos de buena prueba ${ }^{76}$. Con ello se intentó medianamente homologar la rapidez que se producía en el procedimiento establecido en la ley $\mathrm{N}^{\circ}$ 4.447. Los titubeos son porque la omisión de dichos trámites no es un gran alivio para lograr disminuir los tiempos de tramitación de un procedimiento ordinario, pero es algo. No obstante, la simplificación también se produjo en materia de recursos, ya que se instauró el solo efecto devolutivo para la concesión de la apelación y preferencia para su vista y fallo. Así, se evitaban maniobras dilatorias y la promoción de impugnaciones con propósitos espurios ${ }^{77}$. También, se establece la posibilidad de pedir alimentos provisionales por vía incidental.

3. Ahora bien, esta ley dispuso que se aplicaba a las solicitudes deducidas por mayores de 18 años. Para los que estaban bajo dicha edad se continuaba aplicando la ley $\mathrm{N}^{\circ}$ 4.447. Sin embargo, esta última ley, según su normativa, era aplicable a los menores de 20 años, por lo que en la franja comprendida entre los 18 y los 20 años se formó una superposición incoherente de leyes. Lo dicho, teniendo en cuenta que la minoría de edad general establecida en el derecho común en aquella época era hasta los 25 años, para posteriormente se rebajara hasta los 21 años el año $1943^{78}$. Esta antinomia se pudo zanjar entendiendo que la nueva ley $\mathrm{N}^{\mathrm{0}} 5.750$ era especial, ya que se refería específicamente a los alimentos, por lo que se entendía primar sobre la otra que se refería a la protección de la infancia

\footnotetext{
${ }^{73}$ Aguayo Lira, Julio, cit. (n. 46), p. 9.

${ }^{74}$ Actas de discusión legislativa, cit. (n. 36), p. 2219.

${ }^{75}$ Ibíd., p. 2276.

${ }^{76}$ Artículo $1^{\circ}$ de la ley 5750.

${ }^{77}$ Fueyo Laneri, Fernando, cit. (n. 6), p. 594.

${ }^{78}$ Ley $\mathrm{N}^{\circ} 7.612$ de 21 de octubre de 1943.
} 
en general ${ }^{79}$. De esta manera, a los menores de 18 años se les aplicaba el procedimiento de alimentos contenido en la ley de protección a la infancia mientras que a los mayores a esa edad-que seguían siendo menores en esos años-se les aplicaba la reciente ley.

Un mecanismo cautelar que hasta estos días tiene un buen efecto se implantó en esta ley. Este se constituyó en la posibilidad de retener las pensiones por el empleador del demandado. Hasta esa fecha los jueces de menores enviaban una comunicación al patrón del alimentario donde se les comunicaba la resolución judicial que fijaba los alimentos. Esta actuaba como un buen oficio ya que quedaba a la buena conciencia del empleador hacer el descuento. No había un constreñimiento legal. En cambio, desde la ley en comento se estableció una multa en caso de desobediencia a la orden judicial equivalente al doble del monto de lo que se ordenaba retener ${ }^{80}$.

Se confiere mérito ejecutivo a las resoluciones judiciales que fijan las pensiones de alimentos desde que se dictan. Esto quiere decir que se pueden cobrar judicialmente apenas se dicta la resolución que las contiene, sin esperar que estén ejecutoriadas como ocurría hasta ese momento, lo que constituyó una excepción a la norma general que confiere mérito ejecutivo a las resoluciones firmes o ejecutoriadas o que causan ejecutoria de acuerdo al Código de Procedimiento Civil $^{81}$. Esta norma, asimismo, vino a remediar el problema que reportaba la dualidad de tribunales llamados a conocer el conocimiento y eventual ejecución de las pensiones que se exploró en el capítulo cuarto supra. En ese sentido asignó competencia para ejecutar las pensiones impagas al tribunal que dictó la resolución que las imponía en única o primera instancia. El fin de esta norma, como de todas las otras que conforman el cuerpo legislativo en referencia, fue evitar el retardo injustificado del proceso por parte del deudor. Aquella conducta, se estimó por los legisladores, era de esperar en una instancia ejecutiva en su contra ${ }^{82}$, puesto que: "los más encarnizados enemigos de esta ley, son precisamente los individuos demandados que han estado negando, valiéndose de recursos procesales, las pensiones alimenticias durante muchos años a sus hijos" $" 83$.

Unido a esto, con el mismo fin, se restringe el número de excepciones que puede oponer el demandado desde las 18 que establece el Código de Procedimiento Civil a solo una: la excepción de pago. Cuestión que produjo no pocas incertidumbres según dan cuenta las actas legislativas. ${ }^{84}$ Las dudas de la discusión parlamentaria sobre la posibilidad de interponer esta única excepción discurrieron sobre entender que para algunos congresistas no era posible coartar de tal manera el derecho de defensa del deudor, mientras que, para otros, permitir un amplio catálogo de excepciones era posibilitar la dilación del proceso con el consiguiente

\footnotetext{
${ }^{79}$ Aguayo Lira, Julio, cit. (n. 46), pp. 28-29.

${ }^{80}$ Fueyo Laneri, Fernando, cit. (n. 6), p. 596.

${ }^{81}$ Con esto se evitaba "el absurdo actual de obligar a los alimentados a iniciar un juicio ejecutivo cada mes para cobrar sus alimentos". Actas de discusión legislativa, cit. (n. 36), p. 138.

${ }^{82}$ Ibíd., p. 147.

${ }^{83}$ Ibíd., p. 218.

${ }^{84}$ Ibíd., pp. 267, 2758-2760.
} 
abuso que esto podría producir. Esto se refleja con mayor énfasis en el siguiente fragmento de las actas de la sesión legislativa ordinaria del 30 de agosto de 1933: "Yo comprendo que de las 18 excepciones que consulta el Código de Procedimiento Civil para enervar la acción ejecutiva, algunas no procedan [...] pero hay algunas otras señor Presidente, que no pueden por menos que proceder [...]"; a esto replica el diputado Gajardo: "lo que se quiere con esto es matar el tinterillaje" y, a las vehementes réplicas del diputado Vicuña, reafirma lo siguiente: "son los abusos que se cometen hoy en día en esta materia lo que nos obliga a hacer esta clase de leyes", a lo que se le contesta: "esta clase de leyes malas"85. Y así continúa una acalorada discusión sobre lo mismo. Finalmente gana la tesis de incluir un solo medio de defensa en el entendimiento que esto favorecía el rápido cobro de las pensiones y que la posibilidad de deducir todas las defensas y excepciones se agotaban suficientemente en el juicio declarativo de alimentos que precedía a la ejecución, donde no cabía más que pagar a la deuda o demostrar que se había pagado ${ }^{86}$.

Lo que sí se puede notar con nitidez es que este instituto solo fue concebido para un juicio ejecutivo de carácter patrimonial. En aquel tiempo aún no se establecía el sistema de apercibimiento por el cual, si el alimentante no paga, debía cumplir con una medida que le privase de su libertad. Solo se estableció, como se verá más adelante, la posibilidad de perseguirlo penalmente por el incumplimiento, instancia en la cual no era posible oponer excepciones de la manera establecida para la ejecución civil. El procesado podía pagar la deuda en cuyo caso se daba lugar al sobreseimiento definitivo de la causa.

4. En definitiva, prospera la propuesta de considerar un solo medio de defensa para los deudores, asunto que también hoy genera polémica. En efecto, transcurridos más de 70 años, actualmente existe un foco de problemas a partir del tenor de la norma. Particularmente en la aparente contradicción que se produce entre la imposibilidad de deducir la excepción de prescripción por una parte, y, la expresa aceptación de este modo de extinguir las obligaciones que contiene el Código Civil, por la otra ${ }^{87}$, debido a que las pensiones atrasadas son "sin perjuicio de la prescripción que competa al deudor" ${ }^{28}$. Esto último no es de extrañar, si se tiene en cuenta la mirada patrimonialista contenida en el Código de Bello en asuntos de familia desde su génesis de la que no se había desprendido a la fecha de instauración de la ley en comento. Postura que se refleja en el hecho de que las pensiones adeudadas se miran como un crédito personal común y corriente, tal como lo revela el tratamiento que le da el artículo 578 del Código Civil en tanto las asimila a las deudas personales como las que tiene el prestamista en contra su deudor. A esto se agrega que, según Vodanovic, el fundamento de la prescripción

\footnotetext{
${ }^{85}$ Ibíd., pp. 2759-2760.

${ }^{86}$ Ibíd., pp. 2760-2761.

${ }^{87}$ Orrego Acuña, Juan, Prescripción de la acción para obtener el pago de pensiones alimenticias devengadas: doctrina y jurisprudencia reciente, en Revista de Derecho de Familia, 1/5 (2015), pp. 15-35; NúNẼE JiMÉNEZ, Carlos, Sobre la prescripción extintiva respecto de las pensiones alimenticias atrasadas, en Revista de Derecho de Familia, 1/5 (2015), pp. 47-63.

${ }^{88}$ Artículo 336 del Código Civil.
} 
está en el hecho de que si quien las pide pudo subsistir sin que le hayan sido pagadas, las pensiones pierden su finalidad que, desde ese punto de vista, sería la sobrevivencia del alimentario ${ }^{89}$.

Lo peculiar, habida consideración de la discordia actual que genera la norma es que no haya constancia en las actas de discusión legislativa que sobre esta forma de extinguir las obligaciones se haya visualizado algún inconveniente, más allá del general que limitaba el catálogo de defensas del demandado. Al parecer, la discusión se diluyó en la posición que se impuso sobre las demás, por la cual había de entenderse que esta clase de excepción se podía interponer en la etapa de discusión del juicio de lato conocimiento y con eso era suficiente. El inconveniente de esta postura es que, en antaño, al igual que hoy, en esa instancia previa no es posible interponer la excepción de prescripción de las pensiones alimenticias ya que estas aún no se determinan sino hasta la sentencia. Antes de eso existe el derecho de alimentos que en abstracto es imprescriptible. Pero de aquello nadie hizo cuestión y hoy se abre paso a una serie de dificultades que no es del caso citar aqui ${ }^{90}$.

\section{El DELITO DE ABANDONO DE DEBERES FAMILIARES}

$\mathrm{El}$ aspecto más singular de la ley en comento es aquel que establece una figura penal por el incumplimiento de deberes familiares llamado d e li t o de a b a ndono de familia que le dio el nombre a esta ley y que, dicho sea de paso, pretende revivirse a través de una moción que se está presentando actualmente

${ }^{89}$ Vodanovic Haklicka, Antonio, cit. (n. 4), p. 212.

${ }^{90}$ Una panorámica completa de los problemas que genera la prescripción de las pensiones de alimentos se puede encontrar en: Revista de Derecho de Familia, 1/5 (2015). Precisamente se puede suponer que el hecho de que nadie haya notado esta situación es porque, como se dice en el texto, para perseguir el pago de las pensiones los legisladores tenían en mente el diseño que ellos mismos discutieron en el proyecto. Este consistió en que para perseguir el pago de las pensiones existiría un procedimiento civil y bien separado del mismo, en otro tribunal, un procedimiento penal. Dentro de esta estructura bicípite, en el proceso penal no está establecida la posibilidad de oponer excepciones. En realidad, ese mecanismo es completamente extraño a un proceso penal, por lo que no cabía la posibilidad de preguntarse por ello. En este solo se podía pagar en cuyo caso se daba lugar al sobreseimiento de la causa. El problema es que años después, una vez que se deroga la figura penal y de alguna manera se sustituye por la reclusión como una forma de compelir al pago, nadie hace cuestión de esto. A juzgar por las modificaciones legales posteriores que contaban con ningún paliativo a esta situación, y el conocimiento de ambas figuras pasa a un solo tribunal, donde se establece, por una parte, el mismo procedimiento ejecutivo civil y por el otro uno nuevo que funcionaba y funciona hoy en día por medio de los apercibimientos de arresto que puede ser nocturno o total. Para que dicho apercibimiento sea efectivo, se realiza un procedimiento sui generis -ya que la ley no lo establece- mediante el cual previamente se debe liquidar la deuda. A esa liquidación se le abre un plazo de objeción de tres días en que el deudor, aparte de hacer notar errores en el cálculo de la deuda, puede pagar y, donde suelen oponer otra clase de excepciones, entre ellas, la de prescripción tal como si se tratara de un procedimiento ejecutivo, lo que ha dado lugar a un variopinto de soluciones jurisprudenciales que se retratan en el libro que se ha recomendado en esta nota. No obstante, sobre esto se volverá en la segunda parte de esta investigación. 
en el Congreso ${ }^{91}$. En la historia de su establecimiento se cuenta sin muchos preámbulos el motivo específico de la necesidad de su instauración. El diputado Oscar Gajardo en su moción señala: "El Código Civil establece la obligación de los padres de alimentar a sus hijos; pero como esa obligación carece de sanción, es criminalmente burlada por individuos sin conciencia" 92 . En la misma se dan datos estadísticos y empíricos que motivan lo que parece una urgente necesidad de su época: "lo prueba el porcentaje enorme de mujeres abandonadas que acuden con sus pequeñas criaturas a las ollas de racionamiento de los cesantes" 93 . Luego, "en Santiago y Curicó el 70 y 80 \% de los racionados respectivamente son mujeres y niños"

También estos anales ilustran acerca de las legislaciones que sirvieron de referente para esta normativa. Una ley en Francia de 1928 que penalizaba con 3 meses de prisión a 1 año al infractor; una ley inglesa del mismo año que castiga con multa o prisión al padre, madre o tutor, que negligentemente dejan de alimentar, alojar, vestir o cuidar a sus niños; de Suiza que sanciona a los parientes que no proveen sustento y cuidado de sus hijos, entre otras que son también citadas ${ }^{95}$. Conjuntamente se cita la legislación de Estados Unidos que contemplaba el delito de abandono de familia ${ }^{96}$ que está vigente hasta estos días ${ }^{97}$.

Como era de esperar, entre todas las normas que conforman la ley, esta fue la que más causó debate en la discusión parlamentaria entre la facción conservadora y la de izquierda del Congreso. Estos últimos reprochaban a los primeros que se trataba de una legislación que favorecía a los ciudadanos con mayores recursos ya que estimaban que la población de menores ingresos no accedía fácilmente a tribunales a efectuar esta clase de solicitudes. Esta disputa luego se orientó a una serie de otros tópicos entre ambos bandos. Se discutió largamente la posibilidad de que a través de ella se volvía a penalizar las deudas cuya figura penal ya había sido abolida en $1868^{98}$. Finalmente, los congresistas consensuaron de que el injusto que fundamentaba el tipo penal no era una defraudación patrimonial, sino que el dolo que envolvía la actitud de aquel sujeto que pudiendo sustentar las necesidades de su familia, no lo hace. ${ }^{99}$ Estas palabras ilustran con precisión este fundamento: "por prisión por deudas se lleva a la cárcel a los que no tiene como pagar sus obligaciones corrientes; en el delito sobre abandono de familia se sanciona a los que estando obligados a dar alimentos a su mujer o a sus hijos,

${ }^{91}$ Boletín No 12394-18, de 22-01-2019, Cámara de Diputados de Chile, sesión No 129 , primer trámite constitucional.

${ }_{92}$ Actas de discusión legislativa, cit. (n. 36), p. 859.

${ }^{93}$ Ibíd.

${ }^{94}$ Ibíd.

${ }^{95}$ Ibíd., p. 860.

${ }^{96}$ Ibíd., p. 269.

${ }^{97}$ Katz, Elizabeth, Criminal Law in a Civil Guise: The Evolution of Family Courts, en The University of Chicago Law Review, 86/5 (2019), pp. 1241-1310; WikeLEy, Nick, Child Support, Law and Policy (Portland, Hart Publishing, 2006), pp. 148-162.

${ }^{98}$ Aguayo Lira, Julio, cit. (n. 46), p. 38.

${ }^{99}$ Actas de discusión legislativa, cit. (n. 36), pp. 2761-2762. 
por sentencia judicial ejecutoriada, y teniendo los medios pecuniarios para ello, con mala fe y faltando a un sagrado deber, no lo hacen" $"$.

Posteriormente, la discusión se centró en considerar que los fines de la ley no fortalecerían la institución de la familia. Se dijo que quienes reclamarían las pensiones serían aquellos que están fuera de lo que en ese tiempo se entendía por familia: la formada a partir del matrimonio ${ }^{101}$. A la par con esto, se evaluó que una condena afectaría el honor de los hijos y la mujer del condenado, y disminuiría las posibilidades de reconciliación de la familia a la que está obligado a sostener ${ }^{102}$. El sector menos conservador consideraba esta ley como draconiana e injusta, ya que se pensó que no haría distinción entre aquellos padres que no pagaban por una situación de necesidad o malicia. En base a eso, se pensó en sustituir la pena con una multa y si esta no se pagaba, se impondría por vía de sustitución la privación de libertad, lo que finalmente no prosperó ${ }^{103}$. También, se pensó que a la postre fracasaría porque no tendría aplicación general, cual es el fin de toda ley, ya que solo se cometería por aquellos que poseen fortuna que, en Chile, eran la minoría. Así, se dijo que para la gente adinerada no era necesaria una sanción punitiva y solo bastaba con una ejecución patrimonial en su contra para satisfacer el crédito alimenticio. A esto se replicó que precisamente estos sujetos de mayores recursos eran los más culpables, por lo que era meritoria una pena en su contra. Incluso, se justificaba con mayor razón puesto que era muy probable que ocultaran sus bienes ${ }^{104}$.

Finalmente, todos los argumentos se disiparon en concordar que lo más conveniente era la instauración del delito que quedó redactado de la siguiente forma: "Artículo 11. [inc. $1^{\circ}$ ] Será penado con reclusión menor en su grado mínimo, el que estando obligado por resolución judicial ejecutoriada, a prestar alimentos a su cónynge, a sus padres e bijos legitimos o naturales, a su madre ilegitima o a los bijos ilegitimos indicados en el artículo 280 del Código Civil, y teniendo los medios necesarios para bacerlo, dejare transcurrir tres meses para el pago de una cuota de la obligación alimenticia, sin efectuarla. [inc. $2^{\circ}$ ] No podrá ejercitar la acción que concede este artículo, respecto de su marido, la mujer que bubiere sido condenada por adulterio".

El cuerpo normativo también establecía un plazo de prescripción de un año de la acción penal para perseguirlo y la posibilidad de sobreseer definitivamente la causa si mediaba reconciliación entre los interesados o se pagaba la deuda ${ }^{105}$. Transcurrieron 14 años para que los ajustes que la ley $\mathrm{N}^{\circ} 9.293$ de 1949 introdujo a las leyes $\mathrm{N}^{\circ} 5.750$ y $\mathrm{N}^{\circ} 4.447$ sepultaran la figura delictiva por el no pago de los alimentos. Las razones, debido a su profusión y que acontecen en un periodo que excede al considerado en este estudio, se espera que puedan ser abordadas en una segunda parte.

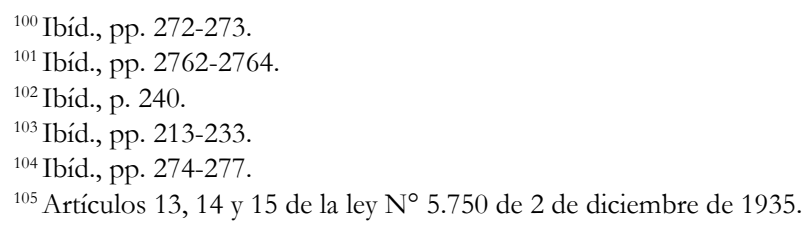




\section{CONCLUSIÓN}

Una perspectiva social y jurídica moderna no permite apreciar con exactitud los fundamentos que cimentaron la ley vigente sobre una materia tan importante para los derechos de los niños como es el pago de pensiones alimenticias. Nótese que incluso su denominación hoy no es muy coincidente con su contenido. El apelativo a b a d o no de familia es tributario de la figura penal que se incorporó en la ley $\mathrm{N}^{\mathrm{0}} 5.750$ de 1935 que hoy no existe y que es la base de la actual ley $\mathrm{N}^{\circ}$ 14.908. El acento de esta última es establecer los mecanismos idóneos para conseguir el pago de las pensiones y de ninguna manera sancionar a quien no ejerce su deber parental, aun cuando parezca deleznable aquella actitud. Pero, más allá de estos problemas semánticos, la importancia de apreciar las bases históricas de la normativa actual, como se ha querido hacer ver a lo largo de esta investigación, se puede encontrar en tres aspectos.

Por una parte, se ha querido que el lector aprecie la interrelación entre los hechos y las normas jurídicas. Más bien, el momento en que la necesidad colectiva da origen a la legislación y la evolución que le precede en base a los continuos cambios sociales. Sobre esto una digresión es importante. En el caso del fenómeno jurídico, particularmente en los sistemas de ley civil, debe considerarse que las normas y sus sucesivas reformas en sí no son el objeto de la historia. Como ha establecido con acierto Lucien Febvre no hay otro objeto de la historia que el hombre en el marco del tiempo. En consecuencia, debe entenderse a las n o r m a s como el resultado de una de las facetas de la expresión humana, más que como un elemento abstracto.

Aclarado lo anterior, en este trabajo se intentó hacer notar que el acervo jurídico de la época de creación de las normas en comento, principios del siglo XX, poseía una mirada patrimonialista y privada sobre el estatuto de las pensiones de alimentos para niños a tal punto que estas eran vistas como una deuda común y corriente. Este enfoque, de acuerdo con lo analizado, comienza a cambiar con la dictación de las primeras leyes que tutelaban específicamente el derecho de la infancia. Esto ocurre a partir de los reclamos de algunos legisladores que representaban los intereses de los sectores más desposeídos de la comunidad en una época donde el empobrecimiento de la población fue de la mano con profundas transformaciones socioculturales que golpearon fuertemente los derechos de la infancia.

Es así como en base a las sucesivas reformas legislativas que se gestaron para remediar esta situación, tres de las cuales fueron vistas en este estudio, la normativa sobre protección de la infancia y en especial la referida al derecho de alimentos fue variando progresivamente a una concepción en la que el Estado comenzó a tomar cartas en este asunto con la dictación de la ley $\mathrm{N}^{\circ} 5.750$ de 1935 . Así, se comienzan a desplazar las consideraciones patrimoniales iniciales sobre este tópico que se abren hacia una de carácter público en la medida que se entiende que el derecho de los niños y el pago de las pensiones de alimentos no es algo que compete únicamente a sus padres, sino que a toda la sociedad.

En segundo lugar, se dieron a conocer los anales que inciden en ciertos nudos críticos que hoy en día se producen con ocasión de la aplicación de la ley 
que actualmente rige el cobro de los alimentos, como el referido a lo que debe entenderse como primera de manda o el relativo a la prescripción, que no han encontrado una solución satisfactoria en elementos gramaticales, lógicos o sistemáticos de interpretación legal. En ese sentido se espera que lo dicho aquí sirva como un insumo sobre el que la dogmática y la jurisprudencia pueda ahondar en base al elemento histórico de hermenéutica normativa para esbozar mejores soluciones a los dilemas que se les plantean.

Finalmente, hay expectativas que las pautas históricas que se han dado a conocer a través de este estudio también puedan orientar a los legisladores para que tengan en cuenta instituciones que en antaño han fracasado y que hoy quieren revivir, como el delito por no pago de pensiones alimenticias, para evitar que la compulsión de los momentos lleve a la dictación de leyes que, si no ha funcionado en antaño, es probable que no funcionen ahora. No obstante, esto merece ciertas y mayores apreciaciones para una comparativa cabal que pretenden ser analizada en una segunda parte.

\section{BiBLIOGRAFÍA}

Fuentes jurisprudenciales

Corte de Apelaciones de Santiago, 24 de julio de 1913, en Gaceta de los Tribunales (1913), pp. 3076-3077.

Corte de Apelaciones de Santiago, sentencia de 11 de enero de 1929, en Revista de Derecho y Jurisprudencia, 27/1 (1930), pp. 139-142.

Corte de Apelaciones de Santiago, sentencia de 23 de junio de 1921, en Revista de Derecho y Jurisprudencia, 20/1 (1923), pp. 461-465.

Corte de Apelaciones de Santiago, sentencia de 24 de diciembre de 1919, en Revista de Derecho y Jurisprudencia, 19/7 (1921), pp. 309-311.

Corte de Apelaciones de Santiago, sentencia de 29 de septiembre de 1922, en Revista de Derecho y Jurisprudencia, 23/1 (1926), pp. 36-39.

\section{Literatura}

Abeliuk Djimino, Joyce; Cerri López, Ximena, Investigación de la paternidad ilegitima y reconocimiento forzado de la paternidad, en Revista de Derecho y Jurisprudencia, 75/1 (1978), pp. 37-54.

Actas de discusión legislativa del proyecto de ley sobre responsabilidad paterna y pago de pensiones alimenticias, sesiones 1933-1955 (Santiago, Biblioteca del Congreso Nacional).

Aguayo Lira, Julio, La ley 5750 sobre abandono de familia y pago de pensiones alimenticias. Análisis y crítica (Santiago, Universidad de Chile, 1944).

Beloff, Mary, Modelo de la protección integral de los derechos del niño y de la situación irregular. Un modelo para armar y otro para desarmar, en Justicia y derechos del niño (Santiago, UNICEF, 1999), pp. 1-15.

Boletín No 12394-18, de 22-01-2019, Cámara de Diputados de Chile, sesión No 129, primer trámite constitucional.

Caffarena de Jiles, Elena, De las pensiones alimenticias ${ }^{2}$ (1947, Santiago, Fallos del Mes, 1986).

Carretta Navea, Darío, La policía de menores. Estudio sobre la delincuencia de menores y un método directo de prevención (Concepción, Universidad de Concepción, 1970). 
Claro Solar, Luis, Explicaciones de derecho civil chileno y comparado (Santiago, Editorial Jurídica de Chile, 1978), I.

Collier, Simon; Sater, William, A History of Chile, 1808-2002 (Cambridge University Press, 2004).

Consolo, Claudio, Spiegazioni di diritto processuale civile (Torino, Giappichelli Editore, 2014), I.

Delzons, Luis, La investigación de la paternidad, en Revista de Derecho y Jurisprudencia, 10/1 (1913), pp. 217-229.

Etcheberry Court Leonor; Veloso Valenzuela, Paulina; Muñoz Sánchez, Andrea, El nuevo estatuto filiativo y las modificaciones al derecho sucesorio, a la luz de las normas y principios de la ley $N^{\circ} 19.585$ (Santiago, Sernam, 1999).

Febvre, Lucien, Los combates por la bistoria ${ }^{3}$ (1970, Barcelona, Ariel, 1982).

Fernández Pradel, Arturo, Hijos naturales, ilegitimos o de dañado ayuntamiento, en Revista de Derecho y Jurisprudencia, 14/1 (1917), pp. 144-149.

Fueyo Laneri, Fernando, Derecho civil (Santiago, Imprenta y Litografía Universo, 1959), III.

Gajardo Contreras, Samuel, Los derechos de los niños y la tiranía del ambiente (Santiago, Editorial Nascimiento, 1929).

- Memorias de un juez (Santiago, Editorial Divulgación, 1957).

—Protección de menores (Santiago, Editorial Jurídica de Chile, 1955).

Gazmuri Riveros, Cristián, Historia de Chile 1891-1994 (Santiago, Ril Editores, 2012).

Greeven Bobadilla, Nel, Derecho de alimentos como derecho humano y apremios para obtener el cumplimiento (Santiago, Librotecnia, 2018).

Grez Toso, Sergio, La "cuestión social" en Chile, ideas y debates precursores, 1804-1902 (Santiago, Dirección de Bibliotecas, Archivos y Museos, 1995).

KaTz, Elizabeth, Criminal Law in a Civil Guise: The Evolution of Family Courts, en The University of Chicago Law Review, 86/5 (2019), pp. 1241-1310.

Mann, Wilhelm, Luchando por nuevas formas de vida (Santiago, Biblioteca Fundamentos de la Construcción de Chile, 2011), I.

Milanich, Nara, Childhood, Class, and the State in Chile, 1850-1930 (Durham, Duke University Press).

NúÑEZ JIMÉNEZ, Carlos, Sobre la prescripción extintiva respecto de las pensiones alimenticias atrasadas, en Revista de Derecho de Familia, 1/5 (2015), pp. 47-63.

Orrego Acuña, Juan, Prescripción de la acción para obtener el pago de pensiones alimenticias devengadas: doctrina y jurisprudencia reciente, en Revista de Derecho de Familia, 1/ 5 (2015), pp. 15-35.

Orrego Luco, Augusto, La cuestión social (Santiago, Editorial Barcelona, 1897).

Ossa Reygadas, Marta, Tribunales de Familia, en Revista de Derecho y Jurisprudencia, 66/2 (1969), pp. 31-82.

Pérez Ragone, Álvaro, El impacto del diálogo entre derecho sustantivo y derecho procesal, en Revista Derecho del Estado. Universidad Externado de Colombia, 41 (2018), pp. 255-283.

Repertorio de legislación y jurisprudencia chilena: Código civil y leyes complementarias (Santiago, Editorial Jurídica de Chile, 1996), II.

Reyes Konings, Luis, La Cuestión Social en Chile: Concepto, problematización y explicación. Una propuesta de revisión historiográfica, en Estudios Históricos, 2 (2010), pp. 1-14.

Rojas Flores, Jorge, Historia de la infancia en el Chile repúblicano, 1810-2010 (Santiago, Junji, 2010).

-Juegos y alegrías infantiles, en Sagredo Baeza Rafael; Gazmuri Riveros, Cristián 
(eds.), Historia de la vida privada en Chile, el Chile moderno. De 1840 a 1925 (Santiago, Taurus, 2011), II, pp. 349-388.

Romero Seguel, Alejandro, Curso de derecho procesal civil (Santiago, Editorial Jurídica de Chile, 2006), I.

SANTELICES, María, El servicio social frente al problema de la madre soltera y su bijo, en Revista Servicio Social, 12/4 (1938), pp. 151-197.

Schonhaut Berman, Luisa, Profilaxia del Abandono: Cien Años de Protección de la Infancia en Chile, en Revista Chilena de Pediatría, 81/4 (2010), pp. 304-312.

Silva Bascuñán, Alejandro, Un siglo de evolución legislativa en lo familiar, en Revista de Derecho y Jurisprudencia, 49/9 (1952), pp. 99-118.

Somarriva Undurraga, Manuel, Derecho de Familia (Santiago, Editorial Nascimento, 1946).

Turner Saelzer, Susan, Los tribunales de familia, en Revista Ius et Praxis, 2/8 (2002), pp. 413-443.

Urrutta, Cecilia, Niños de Chile (Santiago, Editorial Quimantú, 1972), pp. 1-92.

Valdivieso Fernández, Patricio, "Cuestión social" y Doctrina Social de la Iglesia en Chile (1880-1920): ensayo histórico sobre el estado de la investigación", en Revista Historia, 32 (1999), pp. 553-573.

—Dignidad humana y justicia: La bistoria de Chile, la política social y el cristianismo 1880-1920 (Santiago, Editorial Pontificia Universidad Católica de Chile, 2006).

Vodanovic Haklicka, Antonio, Derecho de alimentos ${ }^{4}$ (1987, Santiago, LexisNexis, 2004).

Wikeley, Nick, Child Support, Law and Policy (Portland, Hart Publishing, 2006). 